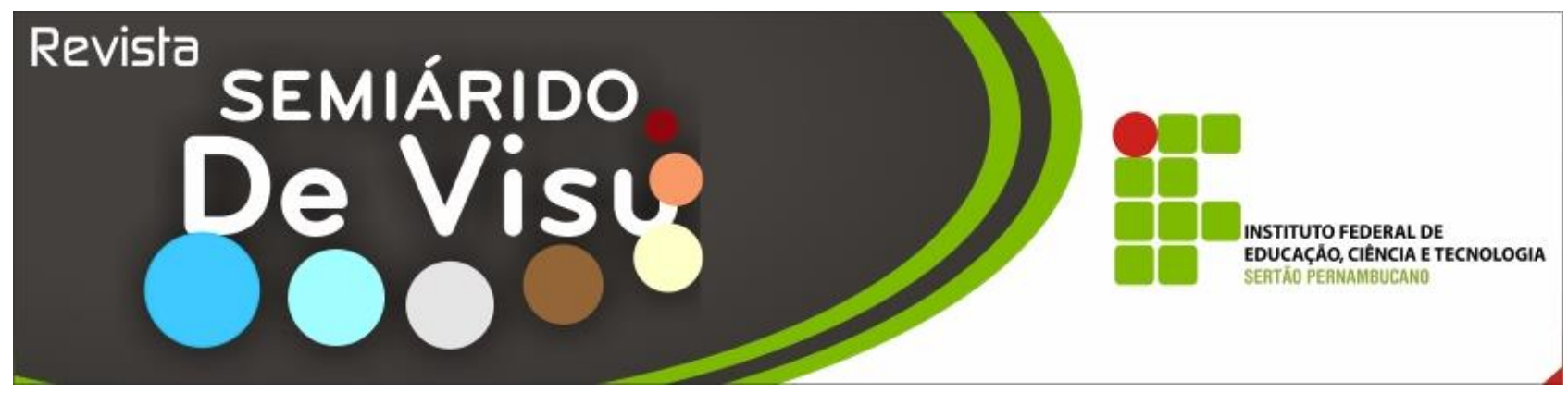

\title{
Uso de instrumento de baixo custo na medição de precipitação pluviométrica no município de Salgueiro - PE
}

\author{
Carlos Wendel Gomes da Silva ${ }^{1}$, Adriana de Carvalho Figueirêdo ${ }^{2}$, Eriverton da Silva Rodrigues ${ }^{3}$, \\ Francisco Lopes Leão Barros ${ }^{4}$ \\ 1,2,3,4. Instituto Federal de Educação, Ciência e Tecnologia Sertão Pernambucano - Campus de Salgueiro. Rodovia Luiz Gonzaga (BR \\ 232), Km 508, Zona Rural - Salgueiro - PE - Brasil. CEP 56000-000 / Telefone: (87) 3421-0050 / E-mail: ${ }^{1}$ cwendel1 @ hotmail.com; \\ 2adrianacarfi78@hotmail.com; ${ }^{3}$ erivertonr@hotmail.com; ${ }^{4}$ francisco.barros@ifsertao-pe.edu.br.
}

\begin{abstract}
RESUMO: Na região semiárida, a precipitação pluviométrica se apresenta de maneira muito variável no tempo e no espaço. O município de Salgueiro-PE, que se encontra inserido nessa região, apresenta apenas dois postos pluviométricos, entretanto, em função da distribuição espacial das chuvas, não é representativo para todo o município. A utilização de instrumentos alternativos de medição de variáveis climáticas se apresenta como uma opção para uso na agricultura ou em práticas de ensino, sem comprometimento da precisão das medidas efetuadas dos fenômenos observados, entretanto é necessário que se conheça e respeite as limitações dos métodos empregados nos instrumentos. O objetivo do trabalho foi avaliar e monitorar a precipitação das chuvas no município de Salgueiro-PE, através do uso de pluviômetro de baixo custo, compreendendo a importância do monitoramento e da avaliação da precipitação, possibilitando verificar o seu comportamento durante o período estudado. Os resultados demostraram que as chuvas se concentraram nos três primeiros meses do ano de 2016, sendo os meses de janeiro e março, respectivamente, os mais chuvosos.
\end{abstract}

Palavras-chaves: semiárido; medidas alternativas, material reciclável.

\section{Low cost instrument for use in rainfall measurement in Salgueiro town - PE}

\begin{abstract}
In the semi-arid region, rainfall is very variable in time and space. The Salgueiro of town - PE, which is located in this region, presents only two pluviometric stations, however, due to the spatial distribution of rainfall, it is not representative for the entire town. The use of alternative instruments for the measurement of climatic variables is presented as an option for use in agriculture or in teaching practices, without compromising the accuracy of the measurements made of the phenomena observed, however, it is necessary to know and respect the limitations of the methods used in the Instruments. The objective of this study was to evaluate and monitor rainfall in the Salgueiro of town - PE, through the use of a low cost rain gauge, including the importance of monitoring and evaluating precipitation, making it possible to verify its behavior during the period studied. The results showed that rainfall was concentrated in the first three months of 2016, with rainy months in January and March respectively.
\end{abstract}

Key words: semi-arid; alternative measures; recyclable material. 
Introdução

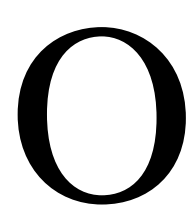

semiárido brasileiro é altamente dependente dos elementos climáticos. Caracteristicamente essa região sempre passou por grandes secas e, mesmo em anos regulares ou bons, a precipitação, que ocorre em apenas quatro meses, inclusive com grande número de dias sem chuva durante a estação chuvosa, sendo marcado pela grande variabilidade espaço-temporal das precipitações (CORREIA et al., 2011).

A fim de realizar medições de chuvas, utiliza-se o pluviômetro como instrumento de medição da altura precipitada, na qual cada milímetro de chuva coletado corresponde a um litro de água por metro quadrado (BORGES et al., 2012).

Seja para utilização na agricultura ou para a prática do ensino, o uso de materiais e métodos de cálculo alternativos pode tornar viável a observação das principais variáveis envolvidas em um balanço hídrico, sem comprometer a necessária precisão das medidas efetuadas dos fenômenos observados, mas para que isso ocorra é necessário que se conheça e se respeite as limitações de cada um desses instrumentos e métodos.

A utilização de instrumentos e métodos alternativos de baixo custo para medir ou estimar parâmetros climáticos, que utilizem materiais acessíveis e que sejam de fácil emprego e cálculo, caracteriza-se como uma possibilidade de superação da ausência ou imprecisão dos dados.

Dessa forma, o uso de pluviômetros alternativos de plástico (comerciais) ou construídos a partir de material reciclável para medir a precipitação pluviométrica em um determinado local é muito comum, devido ao custo de aquisição de um pluviômetro padrão (SOUZA et al., 2013), tornando-se importante para compreensão dessa variável climática, podendo contribuir para a o entendimento do seu comportamento tanto no espaço quanto no tempo em uma região.
Atualmente, o município de Salgueiro apresenta apenas dois postos que registram medições pluviométricas que estão localizados no centro urbano. Com intuito de contribuir com as pesquisas realizadas na área de agricultura e com a compreensão do clima pelos alunos, implantou-se um pluviômetro no IF Sertão PE, Campus Salgueiro, que se localiza na zona rural do município.

Nesse sentido, esse trabalho teve como objetivo avaliar e monitorar a precipitação das chuvas na Fazenda do IF Sertão PE, Campus Salgueiro, através do uso de pluviômetro de baixo custo.

\section{Material e métodos}

O estudo foi realizado na Fazenda do IF Sertão-PE, situada no município de Salgueiro que pertence à bacia do rio Terra Nova, contribuinte da bacia do rio São Francisco, localizado na microrregião do Sertão Central Pernambucano, apresentando uma área territorial de $1.686,815 \mathrm{~km}^{2}$ (IBGE, 2010), entre as coordenadas geográficas de $8^{\circ} 04^{\prime} 27^{\prime \prime}$ de latitude e de $39^{\circ} 07^{\prime} 09^{\prime \prime}$ de longitude, limitando-se ao Norte pelo município de Penaforte - CE, ao Sul por Belém de São Francisco - PE, a Leste por Verdejante, Mirandiba e Carnaubeira da Penha - PE e, a Oeste por Cabrobó, Terra Nova, Serrita e Cedro - PE.

O município se encontra a uma altitude de $420 \mathrm{~m}$. O clima da região é o semiárido quente, com temperatura média anual de $25^{\circ} \mathrm{C}$. A precipitação pluviométrica varia entre 450 a 650 milímetros por ano e os meses mais chuvosos concentram-se de dezembro a março. O Gráfico 1 apresenta a distribuição da precipitação pluviométrica anual e sua média central em 30 anos, os dados foram obtidos no site da Agência Pernambucana de Águas e Climas (APAC) para município, referente a um posto pluviométrico localizado no centro de Salgueiro-PE. A média central dos acumulados anuais foi de $534,15 \mathrm{~mm}$ para a série histórica. 
Gráfico 1: Série histórica de 30 anos de precipitação pluviométrica do município de Salgueiro-PE.

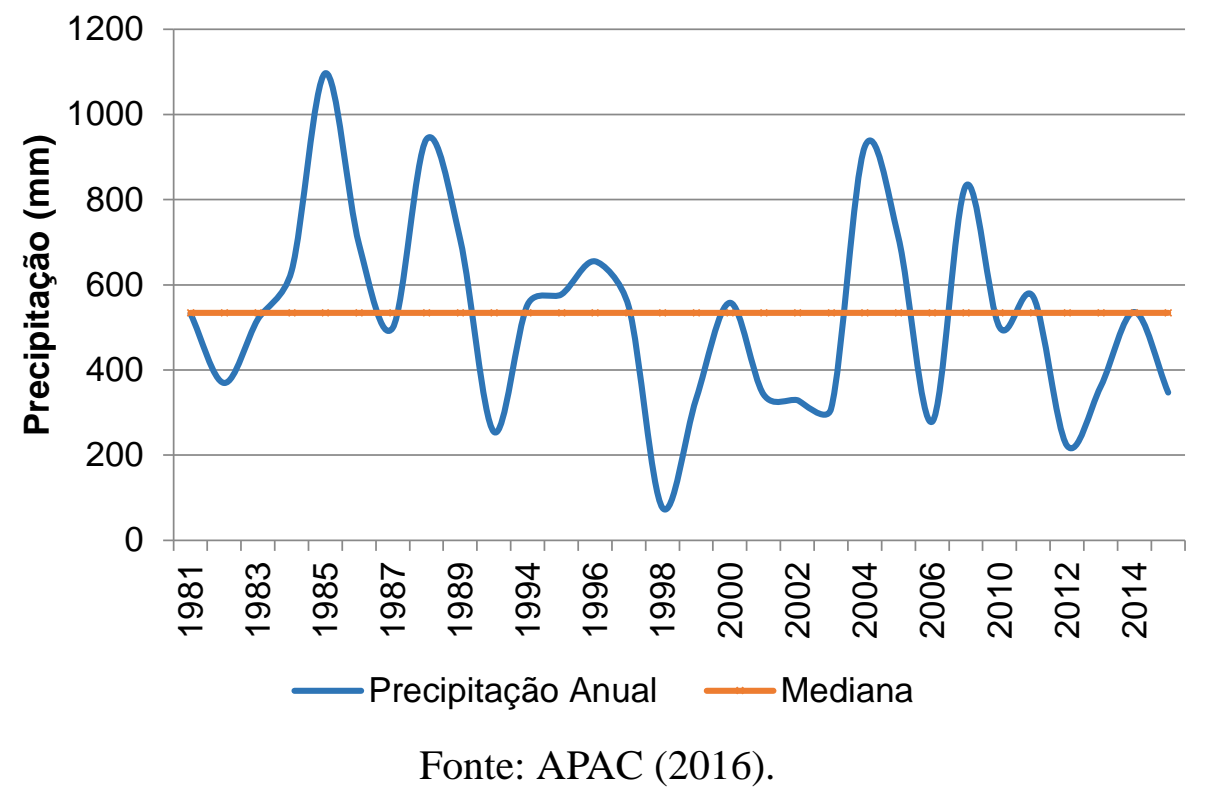

O relevo da região apresenta uma variação de plano e montanhoso. Esse relevo e clima variado faz com que a região seja caracterizada tanto por áreas de sequeiro com chuvas escassas e mal distribuídas, vegetação xerófita e rios temporários; como por áreas de altitude com temperatura amena e bons índices pluviométricos.

As chuvas ocorridas na Fazenda do IF Sertão PE - Campus Salgueiro foram monitoradas por meio de um pluviômetro de PET.

A confecção do pluviômetro foi realizada no referido Campus, com custo que apresenta um baixo valor para sua confecção, quando comparado com os comercializados no mercado, sendo necessários os seguintes materiais: duas garrafas PET de 2,5 L; estilete; tesoura de cortar papel; tesoura de cortar ferro; chapa metálica de 2,0 cm de largura por 36,4 $\mathrm{cm}$ de comprimento; mangueira de $1,5 \mathrm{~m}$ de comprimento e 1/4" de diâmetro; torneira de $1 / 2$ polegada; tinta para plástico (esmalte sintético); solvente; pincel com trincha de 2"; barra de alumínio de uma polegada de espessura e $50 \mathrm{~cm}$ de comprimento; barrote de madeira de 2,0 m de altura; massa de calafetar.

Duas garrafas plásticas de refrigerante de 2,5 litros compõem o pluviômetro. Uma das garrafas foi cortada aproveitando-se apenas o funil, da outra garrafa, retirou-se o tampo da parte inferior e encaixou-se o funil dentro de seu corpo, conforme Figura 1 (MOURA, 2003). Abaixo do instrumento foi fixada uma torneira com massa de calafetar e na área destinada à coleta de chuva, uma borda de alumínio foi utilizada para delimitação (Figura 2). A mangueira de 1/4 de diâmetro foi acoplada de um dos lados à torneira e do outro lado a tampa de uma garrafa utilizada para acumular a chuva diária.

As Figuras 1A e 1B correspondem a etapas da confecção do pluviômetro utilizado nesse estudo e o mesmo instalado em campo. 
Figura 1: Garrafas pet recortadas e encaixadas (A); pluviômetro alternativo pronto para ser instalado (B).
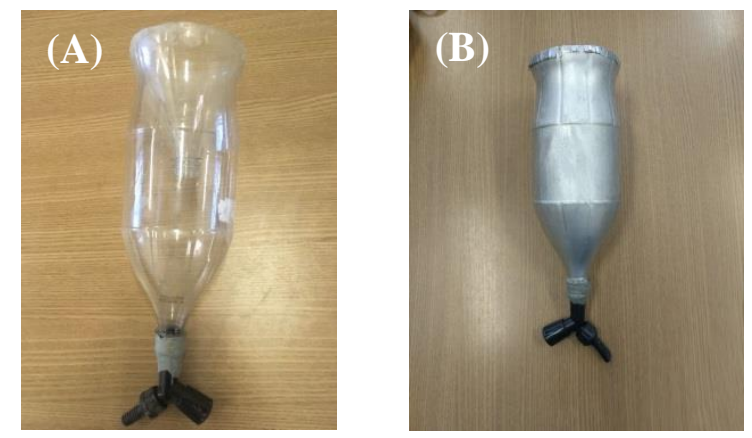

Fonte: Pesquisa direta.

Com o objetivo de promover maior duração para o equipamento e diminuição do erro nas medidas, os mesmos foram limpos a cada três meses. E sempre que necessário, os pluviômetros foram novamente pintados e, em caso de vazamentos, as torneiras e mangueiras trocadas. Tomando estes cuidados, o pluviômetro alternativo poderá durar até cinco anos.

As leituras dos acumulados de chuvas registrados no posto pluviométrico foram realizadas diariamente em horário das 9:00 h da manhã, na ausência ou presença de chuvas, e registrados em planilhas de campo, contendo informações referentes a localização do pluviômetro; responsável pelo registro; data, mês e ano da coleta; dados de chuva.

O registro dos dados foi realizado por meio de leitura da quantidade de chuva que cai na área de captação do instrumento e que é acumulada em garrafa PET. $O$ volume acumulado é conduzido a uma proveta (Figura 2) e medido em $\mathrm{ml}$, para posterior conversão em milímetros.

Figura 2: Bolsista realizando leitura das chuvas acumuladas.

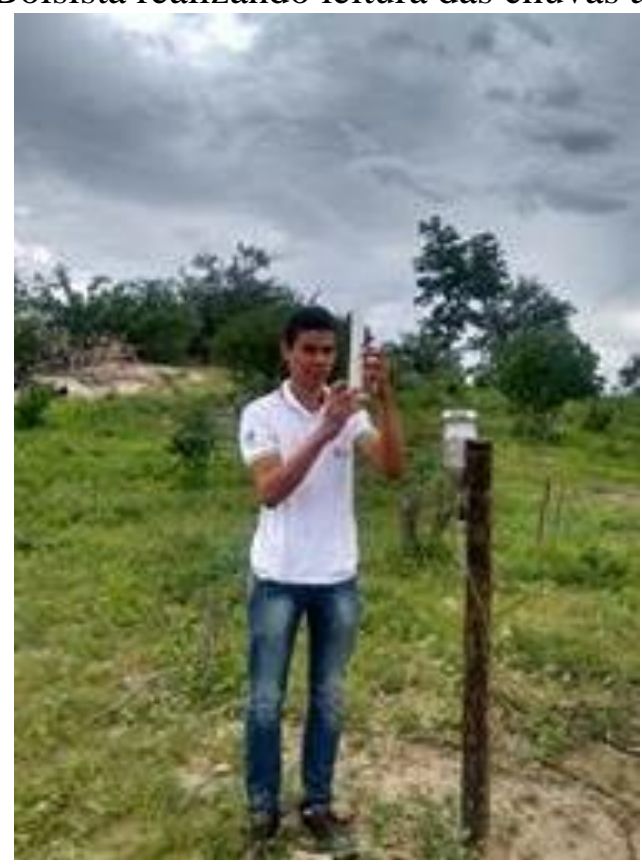

Fonte: Pesquisa direta. 
A conversão da lâmina de água coletada na proveta em mililitro para milímetro foi obtida dividindo o volume coletado pela área de captação do pluviômetro (Equação 1).

$$
\mathrm{H}=\mathrm{V} / \mathrm{S}
$$

Em que: $\mathrm{H}$ é a lâmina de chuva (mm); V é o volume de chuva coletado $(\mathrm{ml})$; $\mathrm{S}$ é a área de captação do pluviômetro $\left(\mathrm{m}^{2}\right)$.

Utilizou-se planilha eletrônica do Excel para tabulação e processamento dos dados e posterior análise e interpretação, por meio de gráficos e valores obtidos.

A tabulação dos dados foi realizada mensalmente após fechamento da planilha com os registros da ocorrência das chuvas.
Os valores de precipitação pluviométrica, cujos dados foram obtidos no site da APAC, foram utilizados para fazer uma comparação entre a distribuição das chuvas na zona urbana e na zona rural (posto IF Sertão PE - Campus Salgueiro), nos meses de estudo.

\section{Resultados e discussão}

O conhecimento da precipitação pluviométrica de uma região se torna importante por ser um elemento climático que varia no espaço e no tempo, sendo necessário realizar o monitoramento dessa variável para diversos fins.

O Gráfico 2 apresenta os dados da precipitação pluviométrica registrados entre os meses de novembro de 2015 a agosto de 2016.

Gráfico 2: Precipitação pluviométrica registrada no fazenda do IF Campus Salgueiro entre os meses de novembro de 2015 a agosto de 2016.

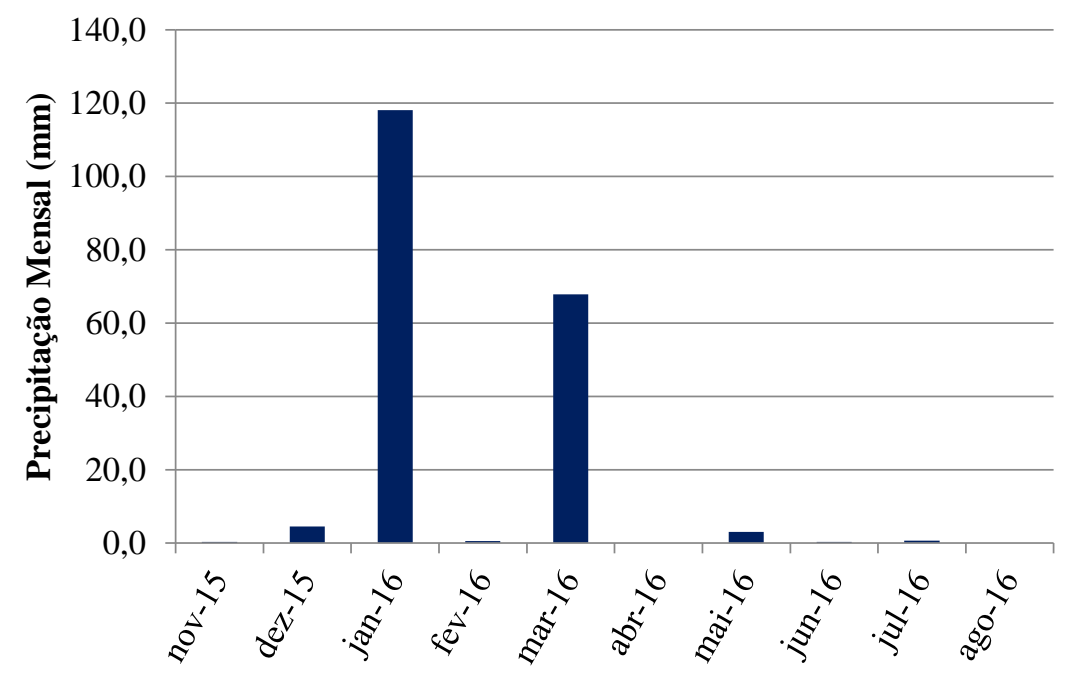

Fonte: Pesquisa direta.

Verificou-se que os meses que apresentaram maiores contribuições de chuvas foram janeiro e março, com acumulados mensais de $118,0 \mathrm{~mm}$ e $68,7 \mathrm{~mm}$, respectivamente.
Esses dados quando comparados aos coletados no site da APAC (2016), para o mesmo período, apresentou a variação espacial das chuvas na região (Gráfico 3). 
Gráfico 3: Precipitação pluviométrica na fazenda do IF Campus Salgueiro e no centro de Salgueiro (dados do APAC) entre os meses de novembro de 2015 a agosto de 2016.

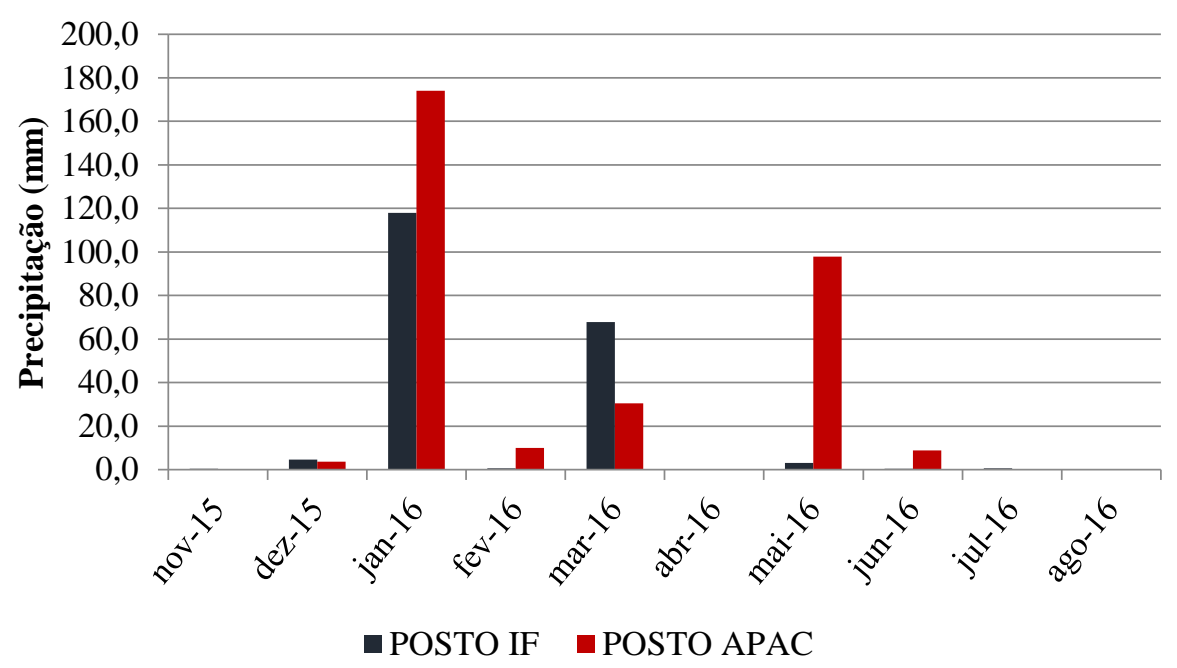

Fonte: Pesquisa direta.

Os dados do centro urbano do município de Salgueiro mostraram que os meses de janeiro $(174,0 \mathrm{~mm})$ e maio $(97,9 \mathrm{~mm})$ de 2016 foram os mais chuvosos no município, diferindo o segundo mês mais chuvoso do registrado no IF Sertão pernambucano Campus Salgueiro. Esses resultados confirmam a variação das chuvas no espaço, quando se percebe que a quantidade de chuvas registradas em localidades diferentes em um mesmo município, podem não ser correspondentes.
O Gráfico 4 apresenta a média mensal das chuvas da série histórica do município de Salgueiro. Observa-se que os meses que compreendem ao período chuvoso da série histórica na região se concentram entre janeiro e abril, com médias históricas de chuvas de $87,0 \mathrm{~mm}, 81,6 \mathrm{~mm}, 130,5 \mathrm{~mm}$ e $86,9 \mathrm{~mm}$, respectivamente.

Gráfico 4: Precipitação média mensal $(\mathrm{mm})$ da série histórica do município de Salgueiro-PE.

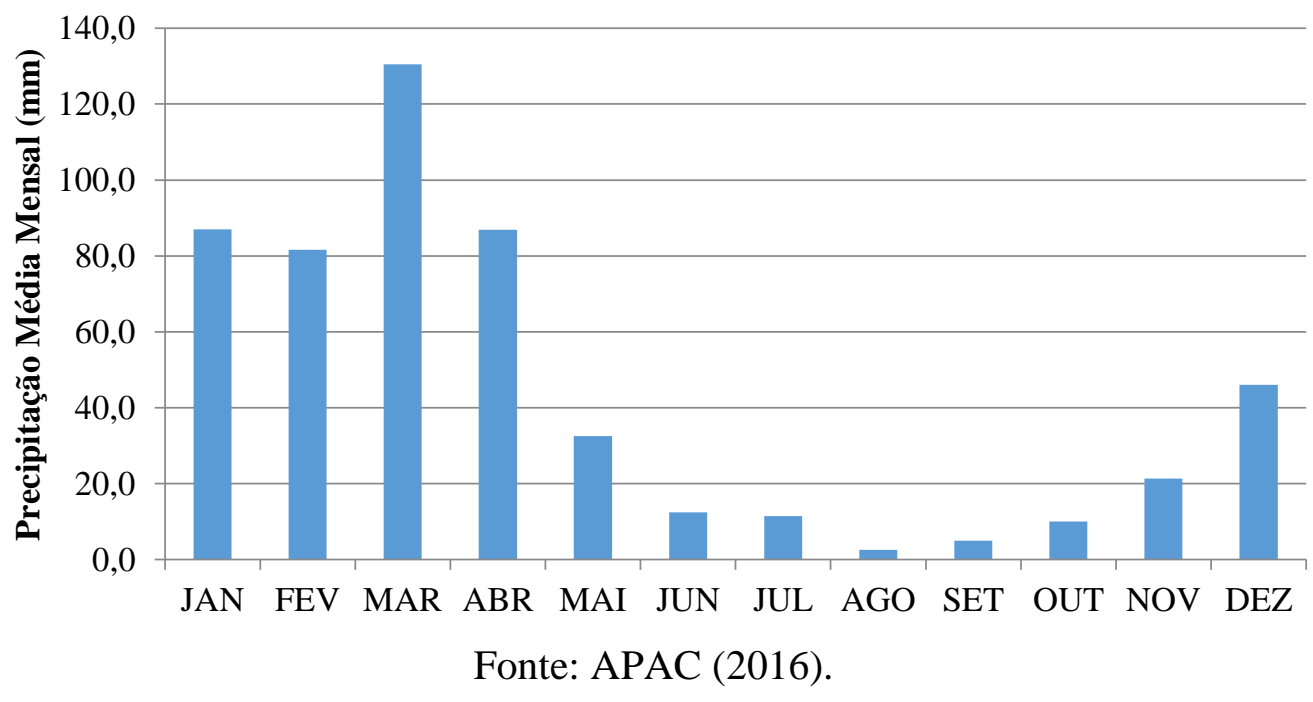

O Gráfico 4 mostra que existe uma variação na distribuição das chuvas dentre os anos, quando comparados aos Gráficos (2 e 3) obtidas para o período de estudo, verificando-se a importância da continuidade do monitoramento. Entretanto, confirma-se o 
período de maiores concentrações de chuva no município.

\section{Conclusões}

$\mathrm{O}$ instrumento mostrou-se eficiente no registro das chuvas correspondente ao período estudado.

Verificou-se a variação nos valores de chuvas ocorridas no município de Salgueiro durante o período de estudo, observando-se que os meses de janeiro e março foram os que apresentaram maiores contribuições de chuvas, no primeiro semestre do ano de 2016, com acumulados mensais de $118 \mathrm{~mm}$ e $68,7 \mathrm{~mm}$, respectivamente.

A comparação dos dados obtidos por meio do pluviômetro alternativo e os dados da APAC mostrou que as chuvas dos dois postos pluviométricos apresentam diferenças na distribuição espacial e temporal.

\section{Agradecimentos}

Agradecemos a Agencia Pernambucana de Águas e Climas pela disponibilidade dos dados de precipitação utilizados nesse estudo.

Ao Programa PIBIC Jr pela concessão da bolsa.

\section{Referências}

APAC - Agencia Pernambucana de Águas e Climas. Monitoramento Pluviométrico. Disponível em <http://www.apac.pe.gov.br/meteorologia/moni toramento-pluvio.php>. Acesso em Agosto de 2016.

BORGES, É. B. M.; PINA, N. V. M.; NASCIMENTO, C. F.; LATUF, M. O. Confecção e Calibração de Pluviômetro como Subsídio à medição de Precipitação. In: Encontro Nacional de Geógrafos, 2012, Belo Horizonte - MG. Entre escalas, poder, ações, geografias, 2012.

CORREIA, R. C.; KIILL, P. L. H.; MOURA, M. S. B.; CUNHA, T. J. F.; JESUS JUNIOR, L. A.; ARAUJO, J. L. P. A região semiárida brasileira. In: Tadeu Vinhas Voltolini. (Org.).
Produção de caprinos e ovinos no Semiárido. Petrolina: Embrapa Semiárido, p. 21-48, 2011.

MOURA, R.F. Dispositivos alternativos para manejo de pequena irrigação familiar, Departamento de Tecnologia Rural, UFRPE, Recife-PE, p. 22, 2003

SCHÄFER, R. F. Precipitação e evapotranspiração de referência estimadas com metodologia alternativa, voltadas à realização do balanço hídrico diário. Dissertação (Mestrado), Curso de PósGraduação em Ciências do Solo/DSEA/SCA/UFPR, 2009.

SOUZA, J.L.M.; SCHÄFER, R.F.; SCHÄFER, H.; JERSZURKI, D. Precipitação medida com pluviômetros alternativos na região de Curitiba (PR). Revista Acadêmica de Ciências Agrárias e Ambiental, Curitiba, v. 11, Supl. 2, p. 83-92, 2013. 